\title{
Functional Classes of Cortical Projection Neurons Develop Dendritic Distinctions by Class-specific Sculpting of an Early Common Pattern
}

\author{
Susan E. Koester and Dennis D. M. O'Leary \\ Molecular Neurobiology Laboratory, The Salk Institute, La Jolla, California 92037
}

\begin{abstract}
We demonstrate in rat neocortex that the distinct laminar arrangements of the apical dendrites of two classes of layer 5 projection neurons, callosal and corticotectal, do not arise de novo, but are generated later in development from a common tall pyramidal morphology. Neurons of each class initially elaborate an apical dendrite in layer 1. Layer 5 callosal neurons later lose the segments of their apical dendrite superficial to layer 4, generating their characteristic short pyramidal morphology. The apical dendrite of layer 5 callosal neurons is actively eliminated, rather than passively displaced, as superficial cortical layers expand. Corticotectal neurons and callosal neurons superficial to layer $\mathbf{5}$ maintain their apical dendrite to layer 1 . Therefore, this selective dendritic loss occurs in a neuron class-specific manner and, within the callosal population, in a lamina-specific manner. Based on our additional observations and other studies, this phenomenon can be extended to other types of cortical projection neurons. These findings show that selective dendritic elimination plays a major role in shaping the functional architecture characteristic of the adult cortex.
\end{abstract}

Functional distinctions between classes of neurons arise in large part from differences in their connections and electrical properties. These differences are most evident in layered neural structures, such as the mammalian neocortex, characterized by ordered laminar arrays of afferents and cell types. The neocortex is divided into six major layers that differ in neuronal morphology and connections. Neurons in different layers have unique dendritic configurations that help determine the functional properties characteristic of the cells (Martin, 1984): the patterning of dendrites contributes to the electrical properties of a neuron (Rall, 1964), while the laminar arrangement of dendrites allows a neuron to sample different sets of afferent information (Gilbert, 1983).

The laminar arrangement of dendrites is especially important for generating distinctions in the functional properties of neurons in the same layer (Martin, 1984; Parnavelas, 1984). Differences in the laminar arrangement of dendrites have been well defined for cells in cortical layer 5 , which contains two major classes of cortical projection ncurons (O'Leary and Stanfield, 1985). In rodents, cortical neurons that send axons across the

\footnotetext{
Received Sept. 25, 1991; revised Nov. 4, 1991; accepted Nov. 8, 1991.

This work was funded by NEI Grant EY07025. Partial support for S.E.K. was derived from an Olin Fellowship awarded through the graduate program at Washington University. We thank Bradley Schlaggar and Rebecca Tuttle for comments on the manuscript and Thomas A. Coogan for helpful discussions.

Correspondence should be addressed to Dr. Dennis D. M. O'Leary, MNL-O, The Salk Institute, 10010 North Torrey Pines Road, La Jolla, CA 92037

Copyright (c) 1992 Society for Neuroscience $0270-6474 / 92 / 121382-12 \$ 05.00 / 0$
}

corpus callosum to contralateral cortex are present in layers 26 , with layer 5 being a prominent source (Wise and Jones, 1976). In addition, layer 5 is the only source of cortical neurons that send axons to subcortical targets in the midbrain, hindbrain, and spinal cord (Wise and Jones, 1977). These two sets of neurons represent distinct projection classes in adult mammals; no layer 5 neurons send axons both across the corpus callosum and to subcortical targets (Miller, 1975; Catsmann-Berrevoets et al., 1980; Swadlow and Weyand, 1981; Wong and Kelly, 1981). This separation in the projections of callosal and subcortically projecting neurons in the adult is apparent even at early stages of axon outgrowth, indicating that these neuronal classes are also developmentally distinct (Koester and O'Leary, 1989).

Studies in adult rodents have demonstrated a major difference in the laminar arrangement of dendrites between corticotectal neurons, which is a population of subcortically projecting layer 5 neurons, and layer 5 callosal neurons (Games and Winer, 1988; Hallman et al., 1988; Hübener and Bolz, 1988). Corticotectal neurons have a thick apical dendrite that tapers gradually over its radial course to layer 1 , where it terminates in a highly branched tuft. Layer 5 callosal neurons, however, have a much shorter apical dendrite that rapidly tapers and usually ends in layer 4 . Such a morphology was first described by Lorente de Nó (1949), who referred to these cells as short pyramids, a population distinct from the classical tall pyramidal morphology characteristic of layer 5 subcortically projecting neurons. Electrophysiological differences between these two neuronal classes have also been described in adult rodents. Layer 5 subcortically projecting neurons have a smaller membrane time constant and input resistance than do layer 5 callosal neurons (Larkman and Mason, 1990; Mason and Larkman, 1990). In addition, subcortically projecting layer 5 neurons show a bursting behavior believed to be responsible for the generation of slow cortical oscillations (Silva et al., 1991).

The distinct dendritic configurations and electrical properties of callosal and subcortically projecting layer 5 neurons define in part their functional specializations. The specificity of their initial axonal projections indicates an early differentiation between these two neuronal classes, suggesting that the differences in their mature dendritic patterning might result from an initially class-specific dendritic growth. However, we demonstrate here that layer 5 callosal neurons initially develop a dendritic configuration similar to that of corticotectal neurons; cells in each class extend and elaborate an apical dendrite in layer 1. Corticotectal neurons retain this apical dendritic arbor. In contrast, layer 5 callosal neurons actively eliminate the superficial parts of their apical dendritc, gencrating thcir characteristic short pyramidal morphology. Therefore, the fate of the apical dendrite of a layer 5 pyramidal neuron can be predicted by the neuron's projection class. 
Table 1. Numbers of animals used

\begin{tabular}{lll} 
& Neuron type labeled \\
\cline { 2 - 3 } Age & Callosal & $\begin{array}{l}\text { Cortico- } \\
\text { tectal }\end{array}$ \\
\hline E18 & 1 & \\
E19 & 2 & \\
E20 & 2 & \\
E21 & 4 & \\
E22 $=$ P0 & 2 & 2 \\
P1 & 4 & 2 \\
P4 & 7 & \\
P5 & 2 & 1 \\
P6 & 2 & 4 \\
P7 & 4 & 1 \\
P9 & & 1 \\
P10 & 4 & \\
\hline
\end{tabular}

A preliminary account of these findings has been presented previously (Koester and O'Leary, 1990).

\section{Materials and Methods}

Animals. Fetuses and pups obtained from timed-pregnant female Sprague-Dawley rats (Harlan) were used (Table 1). The day of insemination is designated as embryonic day (E) 0 . Pups were usually born on E22. The first $24 \mathrm{hr}$ after birth is designated postnatal day (P) 0 .

Animals were deeply anesthetized using either hypothermia (embryos and early neonates) or chloral hydrate $(3.5 \mathrm{mg} / \mathrm{kg}$ body weight) (P6 and older) and perfused transcardially with $10 \%$ formalin in $0.1 \mathrm{M}$ phosphate buffer ( $\mathrm{pH} 7.3)$. The brains were postfixed for $24 \mathrm{hr}$ in the same solution. Placements of $1,1^{\prime}$-dioctodecyl-3,3,3',3'-tetramethylindocarbocyanine perchlorate (DiI) crystals or pressure injections of a solution of $10 \% \mathrm{DiI}$ in dimethylformamide were used to label a large portion of one hemisphere of cortex or the superior colliculus. Typical injection sites are shown in Figure 1 . The brains were stored at $30^{\circ} \mathrm{C}$ for several months to allow DiI diffusion.

Histology. Brains were sectioned at $150 \mu \mathrm{m}$ in a coronal plane using a vibratome. Sections were collected in $0.1 \mathrm{~m}$ phosphate buffer and temporarily mounted on glass slides in the same buffer for viewing. Selected sections were counterstained in a solution of $0.002 \%$ bisbenzimide in $0.1 \mathrm{M}$ phosphate buffer. DiI-labeled neurons were then examined and photographed under rhodamine (for DiI) and UV (for bisbenzimide) optics. Representative neurons were photoconverted in the presence of DAB using the protocol of Sandell and Masland (1988). Photoconverted cells were traced at a $250 \times$ magnification with the aid of a camera lucida attachment.

Quantification. Measurements were made on noncoverslipped sections mounted on glass slides in $0.1 \mathrm{M}$ phosphate buffer using a micrometer inserted in the eyepiece of the microscope. Cells were scored as having an apical dendrite extending to the pial surface or not. Cell height was measured from the center of the cell body to the most superficial tip of the apical dendrite. Cortical depth measurements were taken at the same sites where labeled cells were measured. These depth measurements were taken from the pial surface to the top of subcortical white matter. In an effort to reduce error due to sectioning artifact, only those cells with somas in the middle one-third of the section were counted and measured. Cells with an apical dendrite that ended bluntly were not used for height measurements.

\section{Results}

To examine the development of dendritic distinctions between classes of projection neurons, we used the postmortem method of DiI labeling in aldehyde-fixed brains (Godement et al., 1987; Honig and Hume, 1989). When used in aldehyde-fixed tissue, DiI applied to axons labels neurons in their entirety. Thus, DiI may be used as a retrograde tracer to identify specific classes of
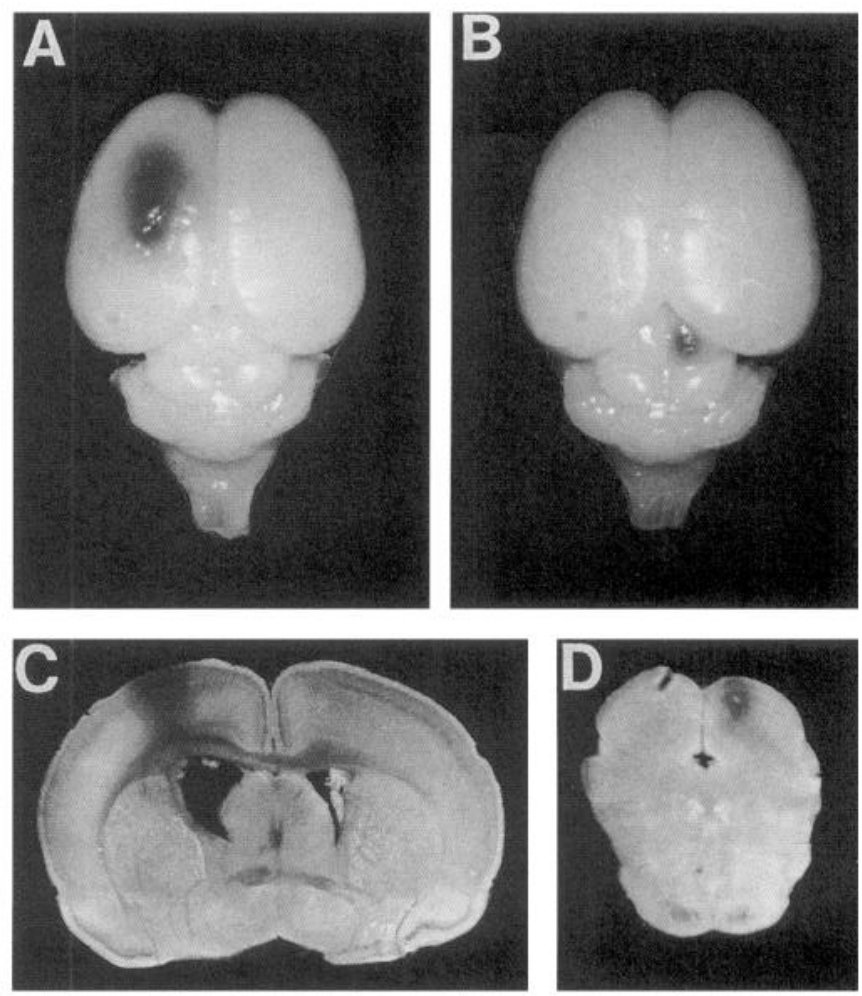

Figure 1. Typical Dil injection sites in cortex $(A, C)$ and superior colliculus $(B, D)$ of $\mathrm{P} 4$ rats. $A$ and $B$ are photos of the dorsal surface of whole brains; $C$ and $D$ are coronal sections through the same brains.

projection neurons and at the same time reveal the complete dendritic morphologies of the labeled neurons. In this study, large injections of DiI were made in contralateral cortex to label callosal neurons or in the ipsilateral superior colliculus to label corticotectal neurons (Fig. 1) in rat brains fixed with aldehydes at several embryonic and postnatal ages (Table 1). The retrogradely labeled neurons are widely distributed across the cortex.

\section{Adult morphology is present by $P 10$}

Using the postmortem DiI technique, we find that at P10 layer 5 callosal neurons have their characteristic short pyramidal morphology (Fig. $2 A$ ) previously described in adult rodent cortex (Lorente de Nó, 1949; Games and Winer, 1988; Hallman et al., 1988; Hübener and Bolz, 1988). At P10, these neurons have apical dendrites that rarely extend beyond layer 4 . These dendrites taper, ending as simple, fine processes. A small number of obliquely oriented branches extend from the apical dendrite in layers 5 and 4 . Layer 5 corticotectal neurons retrogradely labeled in P9 or P10 rats exhibit the classical tall pyramidal morphology typified by a large-diameter apical dendrite that tapers over its radial course to the pial surface (Fig. $2 C$ ). The apical dendrite branches superficially in cortex and arborizes extensively in layer 1 . Occasionally the apical dendrite of corticotectal neurons branches deeper in cortex, sending two major dendrites into layer 1 . Oblique branches off the apical dendritic shaft are usually present only in layers 5 and 4 .

\section{Neonatal and embryonic projection neurons have the same dendritic morphology}

To address the development of this difference in the laminar arrangement of the apical dendrites of callosal and corticotectal 
Figure 2. Adult dendritic morphologies of layer 5 callosal and corticotectal neurons are present by $\mathrm{P} 10 . A$, Layer 5 callosal neurons have a short pyramidal morphology at P10. Their apical dendrites end in layer 4 in a simple bifurcation. $B$, A similar field in an adjacent section counterstained with bisbenzimide to demonstrate cortical lamination. $C$, Corticotectal neurons at $\mathrm{P} 9$ have elaborate apical dendrites that branch extensively in layer 1 . $D$, An adjacent field of the same section counterstained to show cortical lamination. Scale bar, $100 \mu \mathrm{m}$.
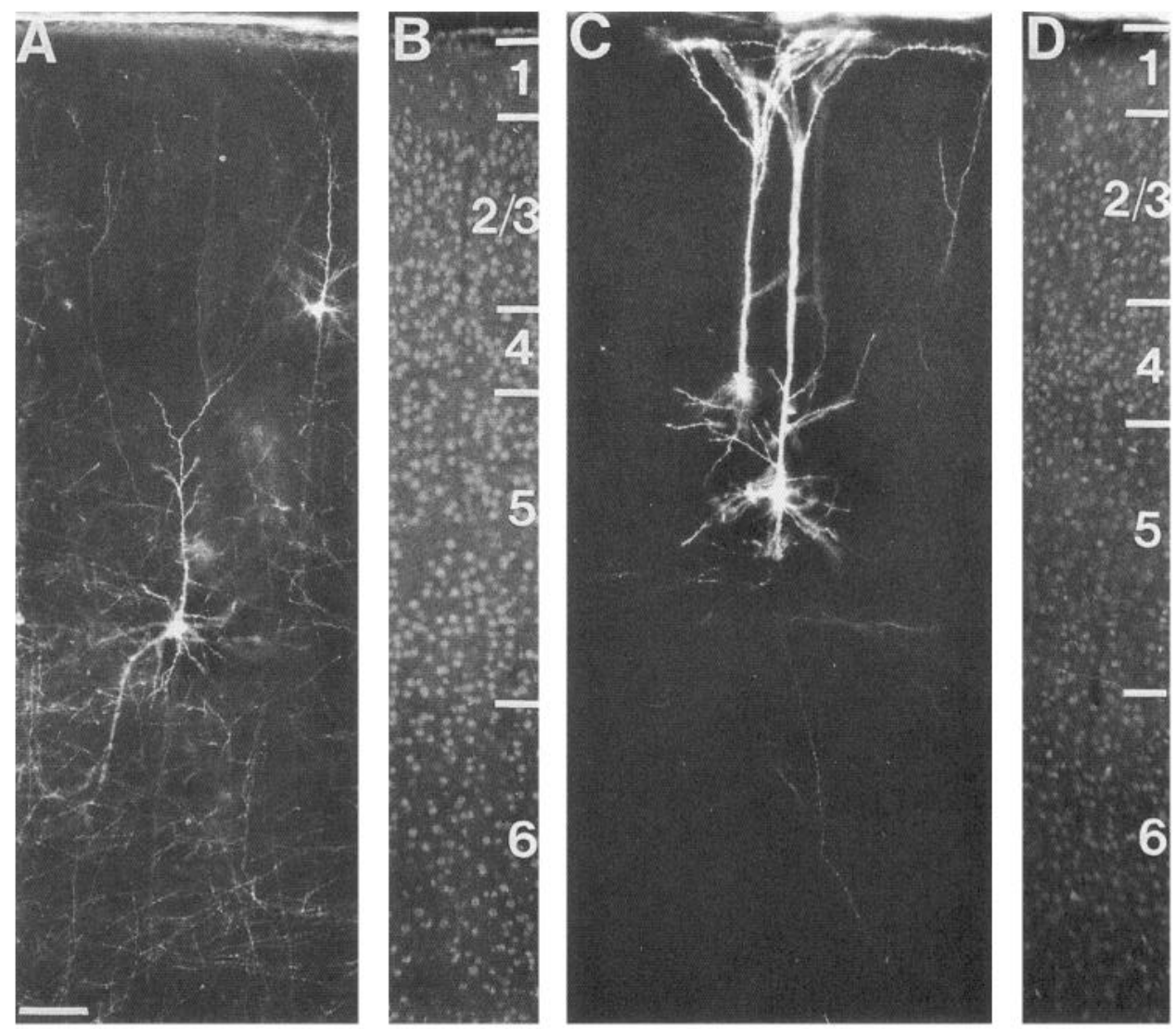

neurons, we examined their dendritic morphologies beginning with the earliest stages that they can be identified by retrograde labeling. In rats, cortical axons first cross the midline through the corpus callosum on E18 (Valentino and Jones, 1982) and invade the contralateral cortical plate on E19 (Catalano and Killackey, 1989). DiI injected into the dorsolateral part of one cortical hemisphere on E18 does not label cells in the contralateral cortical plate, but similar injections done on E19 label a substantial number of cells, most of which are located in the deep part of the cortical plate. At this stage, virtually all of the retrogradely labeled callosal neurons extend an apical dendrite to layer 1 (Fig. $3 A$ ). The apical dendrites frequently branch in layer 1 , but branches are not observed along their lengths. Most if not all of the labeled deep cells are layer 5 and 6 callosal neurons, since previous ${ }^{3} \mathrm{H}$-thymidine birth-dating studies indicate that by E19 layer 5 and 6 neurons occupy the deep part of the cortical plate (Bayer and Altman, 1991). Conceivably, some of the labeled deep cells could be callosal neurons that would come to occupy more superficial layers of the cortex. This scenario requires that migrating callosal neurons extend an axon well into contralateral cortex. However, recent evidence indicates that in rodents migrating callosal neurons do not extend axons into contralateral cortex (Hernit et al., 1990). In brains fixed at E20 and E21, again the majority of retrogradely labeled callosal neurons are deep in the cortical plate and essentially all extend apical dendrites into layer 1 (not illustrated).

P1 is the earliest age at which cortical neurons can be retrogradely labeled from the superior colliculus (DeCarlos and O'Leary, 1992). At P1, the dendritic morphologies of callosal and corticotectal neurons are qualitatively similar. We find that every labeled corticotectal neuron (98 neurons scored in two brains) has developed its characteristic tall pyramidal morphology typified by an apical dendrite that branches in layer 1 (Fig. 3C). In addition, essentially all retrogradely labeled callosal neurons extend an apical dendrite into layer 1. Many of these callosal neurons are clearly in layers 5 and 6 , which by this age have differentiated from the cortical plate (Lund and Mustari, 1977). This laminar positioning is verified by the location of the corticotectal neurons, which are restricted to layer 5 at this age (Fig. 3B,C) (DeCarlos and O'Leary, 1992). Both projection classes have begun to extend oblique branches from the shaft of the apical dendrite.

We have quantified the percentages of deep callosal neurons that extend apical dendrites into layer 1 at these early stages. Since sectioning artifact can cause a dendrite to appear to end in deeper layers of cortex, we only scored neurons in the middle $50 \mu \mathrm{m}$ of the $150-\mu \mathrm{m}$-thick sections. At E19, 83\% of 139 deep callosal neurons scored have apical dendrites in layer 1 . This percentage increases to $90 \%$ at E20 and $97 \%$ at both E21 and P1. However, these figures underestimate the actual percentages, because scoring only cells in the middle third of the section minimizes sectioning artifact but does not eliminate it. Indeed, apical dendrites scored as ending deep to layer 1 at these ages terminate bluntly rather than in fine processes or branches, indicating that they have been sectioned. The lower percentages on E19 and E20 can be explained by two factors. First, due to the greater curvature of the cortical hemisphere at these early stages, it is more difficult to cut radially aligned sections than at later ages; thus, the cutting artifact is greater. Second, some apical dendrites may still be growing superficially and have yet 
to reach layer 1 . These data demonstrate that corticotectal neurons and deep layer callosal neurons initially have a similar morphology characterized by an apical dendrite ending in layer 1 .

\section{Emergence of dendritic distinction}

To determine when deep callosal neurons develop their short pyramidal morphology, we retrogradely labeled cortical neurons with DiI from contralateral cortex or superior colliculus in brains aldehyde fixed at several ages from P4 to P10. The typical appearance of neurons labeled from each of these targets on P4 is shown in Figure 4, $A$ (callosal) and $C$ (corticotectal). Deep callosal neurons continue to elaborate their apical dendritic tuft in layer 1 and extend obliquely oriented branches along the entire apical dendrite. Corticotectal neurons also extend oblique branches from the apical dendrite, but these branches are restricted to its proximal half. Virtually all callosal neurons maintain the tall pyramidal morphology at P5; 97 of 99 deep callosal neurons scored have an apical tuft in layer 1 . The remaining two neurons show a transitional morphology more commonly seen at P7, with an apical dendrite that gradually tapers and ends deep to layer 1 . We do encounter labeled cells, both callosal and corticotectal, with apical dendrites that end bluntly deep to layer 1 , but these are not considered further since the apical dendrites have clearly been sectioned. Indeed, in such instances in cases with a low density of labeled neurons, we can reconstruct the entire apical dendrite and find that it ends in layer 1 on an adjacent section.

At P7, corticotectal neurons further elaborate their tall pyramidal morphology (Fig. $5 E, F$ ). Branches of the apical tuft continue to grow, often extending over $100 \mu \mathrm{m}$ tangentially in layer 1 . In contrast, a large number of deep callosal neurons no longer extend an apical dendrite into layer 1 (Fig. 5A-D) and appear to be transition forms between the early tall morphology and the short pyramidal form characteristic of the adult. It is our impression that the deepest of the layer 5 callosal cells most closely resemble the mature form, as shown in Figure $5 A$, although we have not quantified this trend. Another commonly seen transition form is illustrated in Figure $5 C$. This neuron extends an apical dendrite into the upper part of layer 2. However, this dendrite is extremely thin and does not exhibit the apical tuft typical of deep callosal neurons at earlier ages, or corticotectal neurons at P7. Several oblique branches can be observed along the apical dendrite.

By P10, most deep callosal neurons closely resemble the short pyramids of the adult cortex. A few deep callosal neurons retain an apical dendrite to layer 1 , although it is generally much thinner than the apical dendrite of corticotectal neurons at the same age. The cell bodies of these remaining tall callosal neurons are found superficially in layer 5 , along the border with layer 4 . All callosal neurons deeper in layer 5 are short pyramids. These findings show that the transition from the tall to short pyramidal morphology by deep callosal neurons begins late in the first postnatal week and is largely complete by P10.

Two sets of observations show that the deep callosal neurons that have an early tall morphology are the same population that later have a short pyramidal form. First, as described above, during the period that the transition in dendritic form occurs, we observe layer 5 callosal neurons with apical dendrites intermediate between the early tall morphology and the mature short pyramidal form. Second, previous studies have shown that deep callosal neurons retrogradely labeled during the first post-
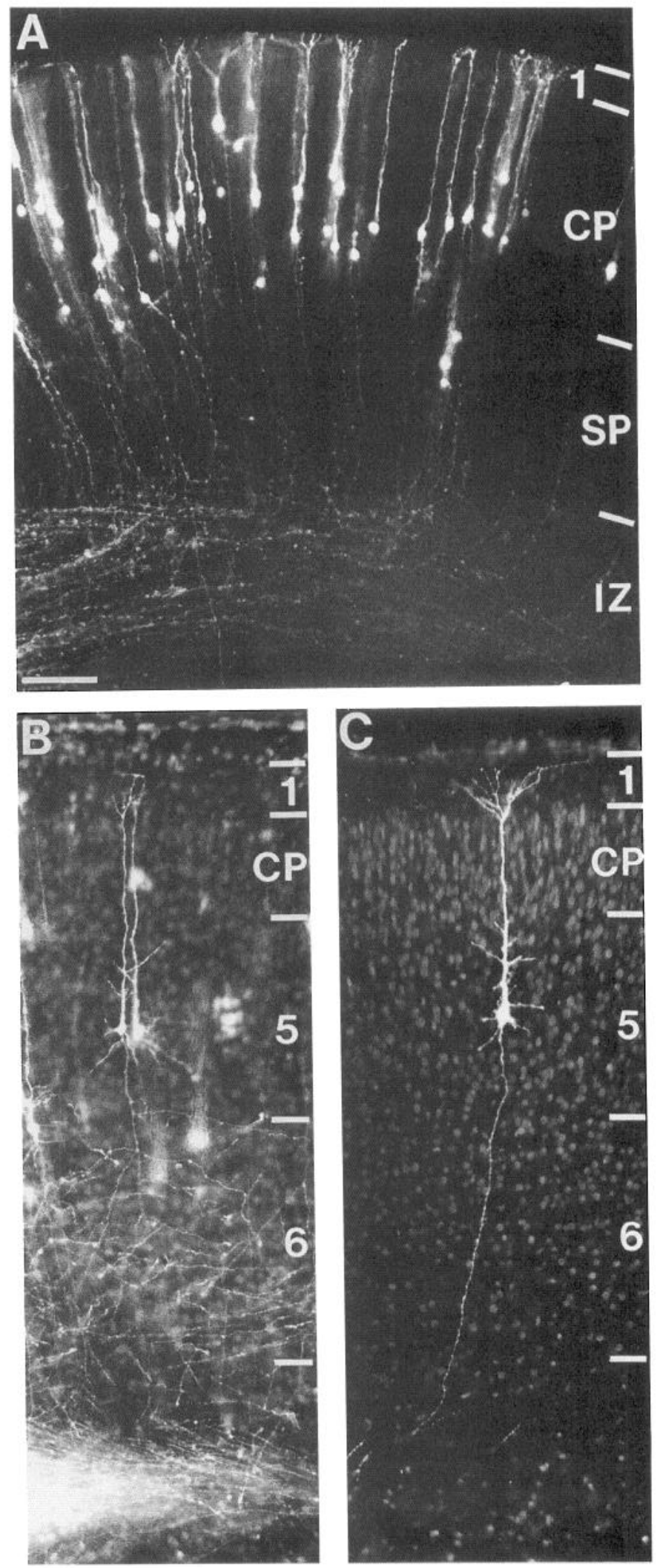

Figure 3. Early dendritic morphology of callosal and corticotectal layer 5 neurons. $A$, Retrogradely labeled deep-layer callosal neurons at E19 with apical dendrites extending into layer $1 . B$, Callosal neurons at P1 with apical dendrites extended into layer 1 . At this age layer 5 has differentiated from the cortical plate $(C P)$. $C$, Corticotectal neurons at $\mathrm{P} 1$ also extend an apical dendrite into layer $1 . B$ and $C$ are counterstained with bisbenzimide. $S P$, subplate layer; $I Z$, intermediate zone. Scale bar, $100 \mu \mathrm{m}$. 

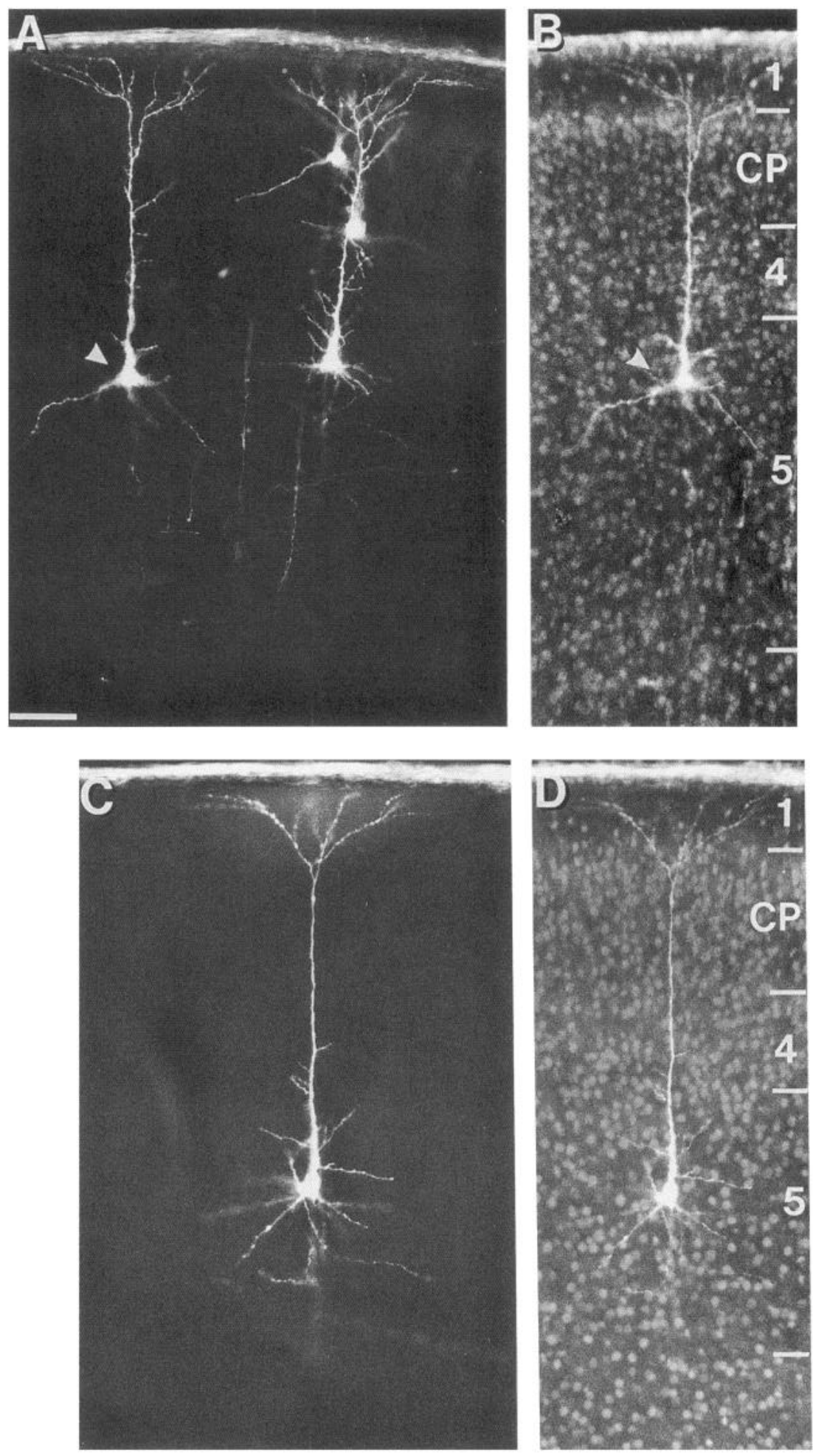

Dendritic morphologies of callosal and corticotectal neurons remain qualitatively similar at P4. A, Layer 5 callosal neurons at $\mathrm{P} 4$ retain apical dendrites in layer $1 . B$, Same section as $A$ counterstained to show cortical lamination. Arrowheads in $A$ and $B$ point to the same neuron. $C$, Corticotectal neuron at P4. D, Same section as $C$ counterstained. $C P$, cortical plate. Scale bar, $100 \mu \mathrm{m}$.

natal week can be relabeled from the contralateral cortex with a second retrograde tracer in mature rats (O'Leary et al., 1981; Ivy and Killackey, 1982). These observations rule out the improbable scenario that the early tall, deep callosal neurons are completely and rapidly replaced by a separate, latent callosal population of deep short pyramids that do not extend a callosal axon until the second postnatal week.
Transition in morphology occurs by selective dendritic elimination

The transition of deep callosal neurons from the tall to short pyramidal morphology could occur by passive displacement or active elimination of the apical dendrite. The cortex increases considerably in thickness during early postnatal life; much of 

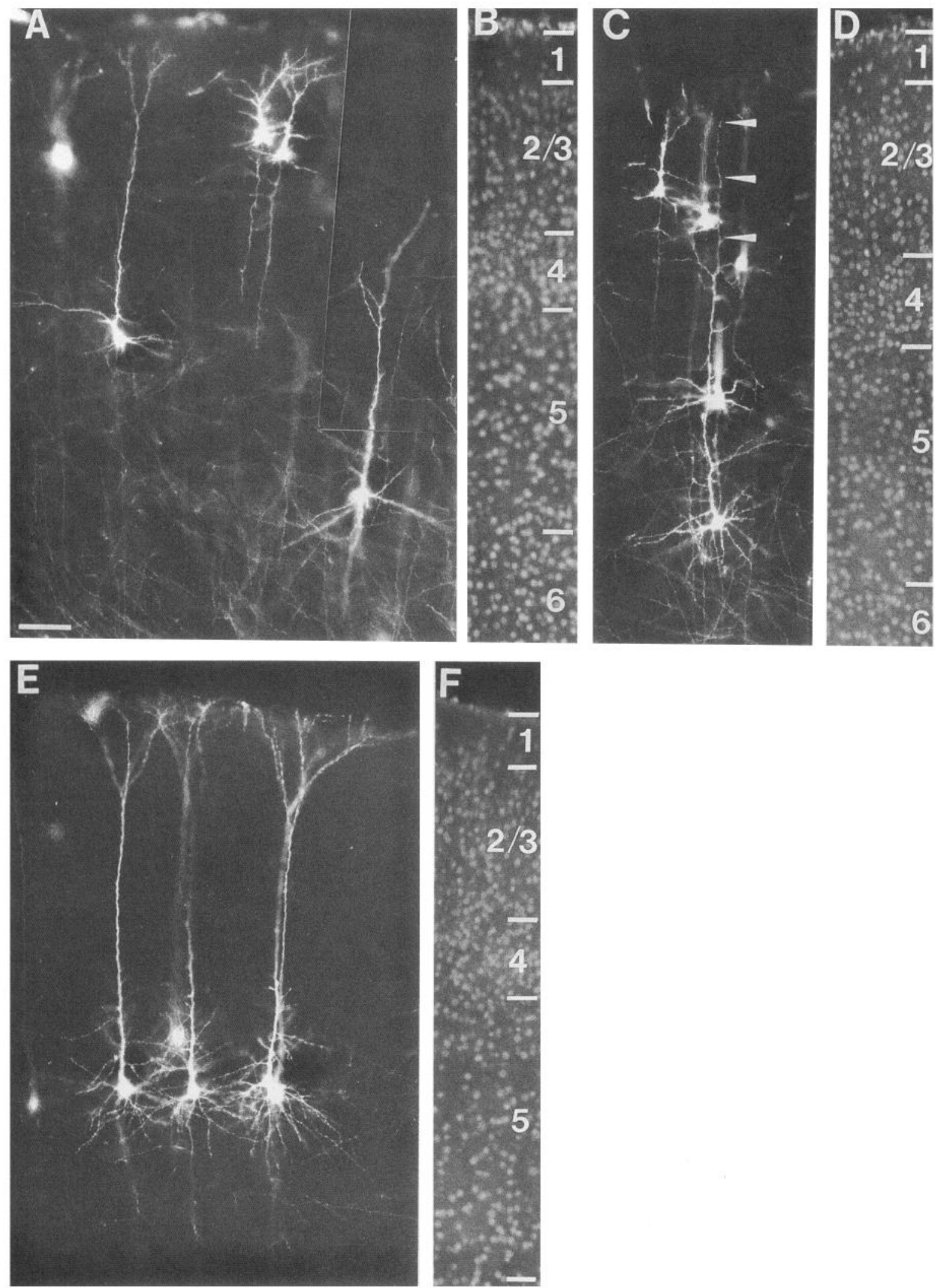

Figure 5. Dendritic morphology of layer 5 callosal neurons begins to become distinct from that of corticotectal neurons by P7. B, $D$, and $F$ are the same fields as $A, C$, and $E$, respectively, counterstained with bisbenzimide. $A$ and $B$, Deep layer 5 callosal neurons have begun to lose their apical dendrite to layer 1, while a more superficial layer 5 callosal neuron retains it. $C$ and $D, \mathrm{P} 7$ callosal transition form. The apical dendrite tapers and ends in upper layer 2, indicated by arrowheads. Oblique branches have formed along most of the apical dendritic shaft. $E$ and $F$, P7 corticotectal neurons retain their layer 1 apical dendrite. Oblique dendrites are usually limited to the deep part of the apical dendrite. Scale bar, $100 \mu \mathrm{m}$. 


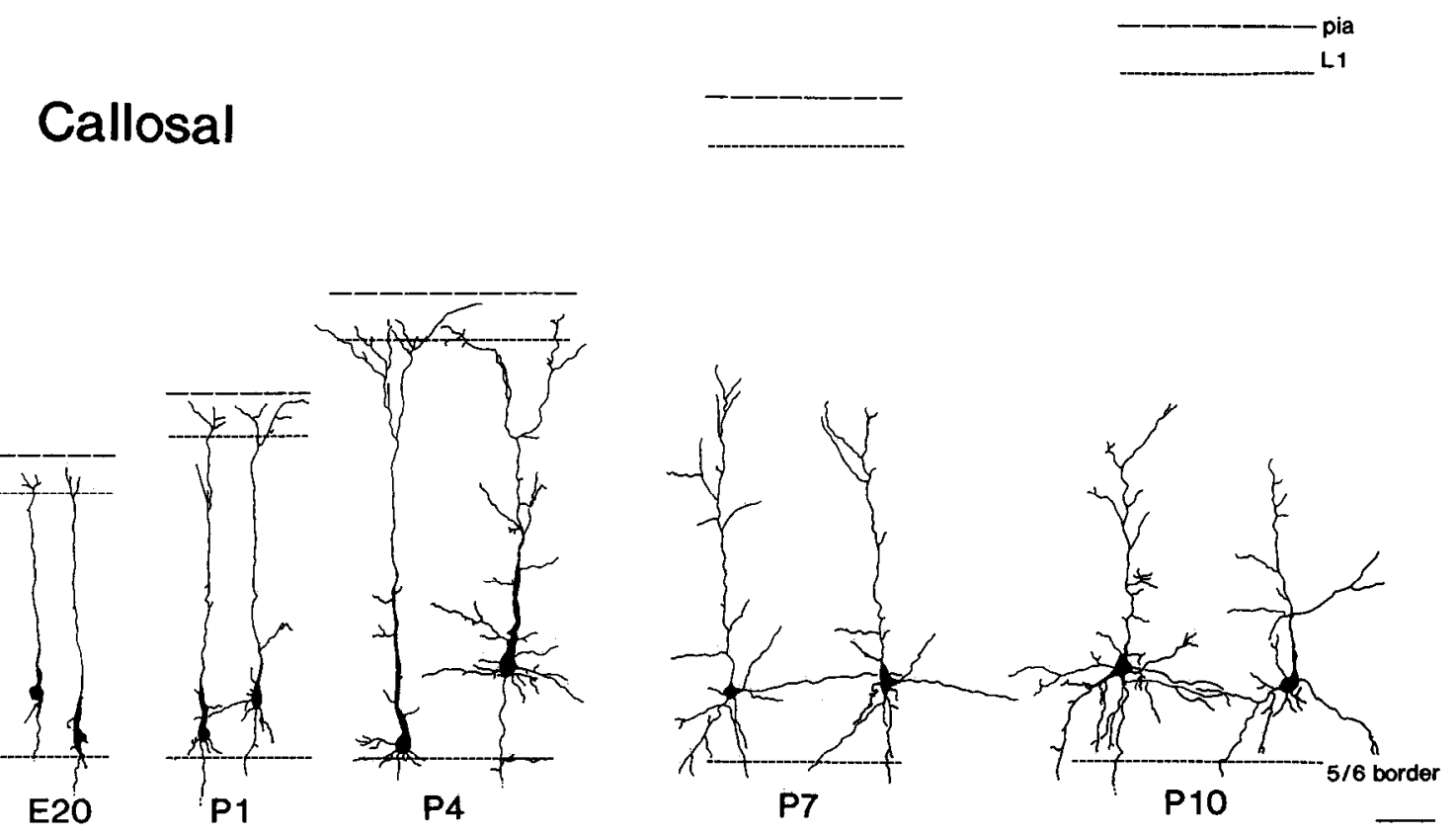

\section{Corticotectal}
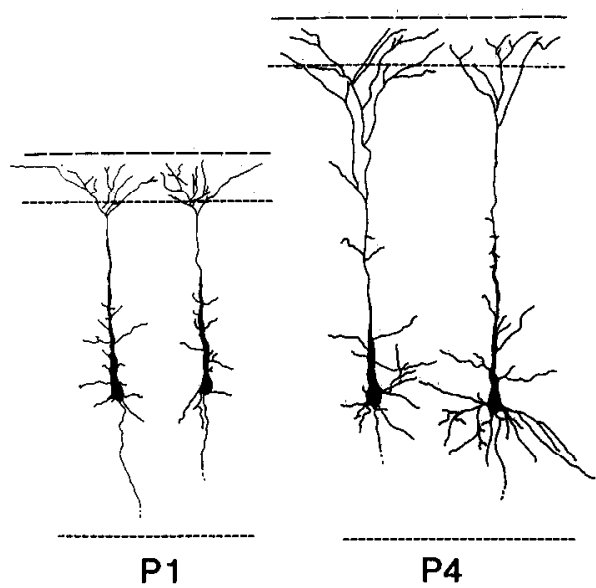

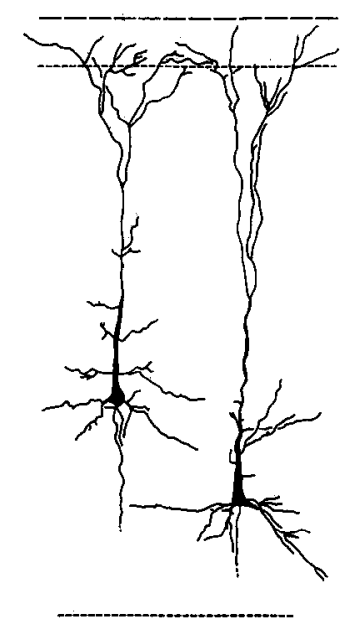

P7

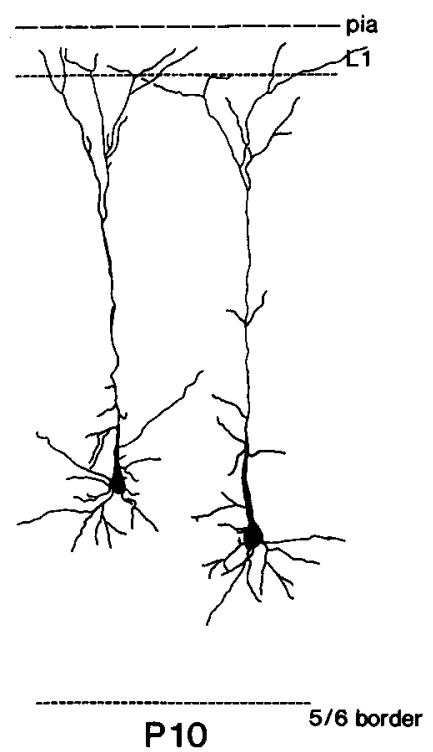

Figure 6. Representative layer 5 callosal and corticotectal neurons retrogradely labeled from contralateral cortex or superior colliculus to show transition in morphology of apical dendrites. Top, Layer 1 apical dendrites of deep callosal neurons increase in height and complexity up to P4, after which they become less complex and shorter. Bottom, Corticotectal neurons continue to elaborate apical dendrites in layer 1 over the same time period. The pial surface, layer $1(L I)$, and the layer $5 / 6$ border are indicated. Each cell is drawn using a camera lucida attachment from a single $150 \mu \mathrm{m}$ section after the DiI labeling was photoconverted. Scale bar, $100 \mu \mathrm{m}$.

this expansion occurs in the superficial layers. Thus, deep callosal neurons may simply fail to elongate at a rate that would allow them to maintain an apical dendrite in the superficial layers. Alternatively, the apical dendrites could be actively eliminated either by resorption or degeneration of their superficial segments. To distinguish between these alternatives, we measured the heights of the apical dendrites at several postnatal ages. A passive mechanism would predict that the average height of deep callosal neurons reaches a peak and then plateaus, while cortical thickness continues to increase. However, our qualitative observations, illustrated in Figure 6, show that callosal neurons first increase in height up to P4, but later decrease in height as they achieve the short pyramidal morphology. Quantitative measurements of dendritic height (Fig. 7) support these observations. Callosal neurons show statistically significant decreases in height between P4 and P7 and between P7 and P10 (Student's $t$ test, $p<0.01$ ). In contrast, the height of corticotectal neurons increases over this period (Figs. 6, 7). These data dem- 
A HEIGHT OF LAYER 5 CALLOSAL NEURONS

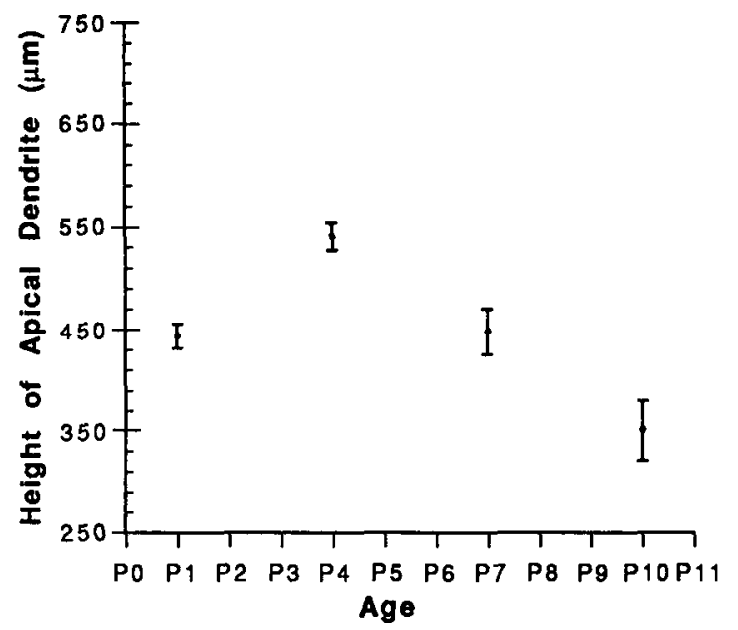

B

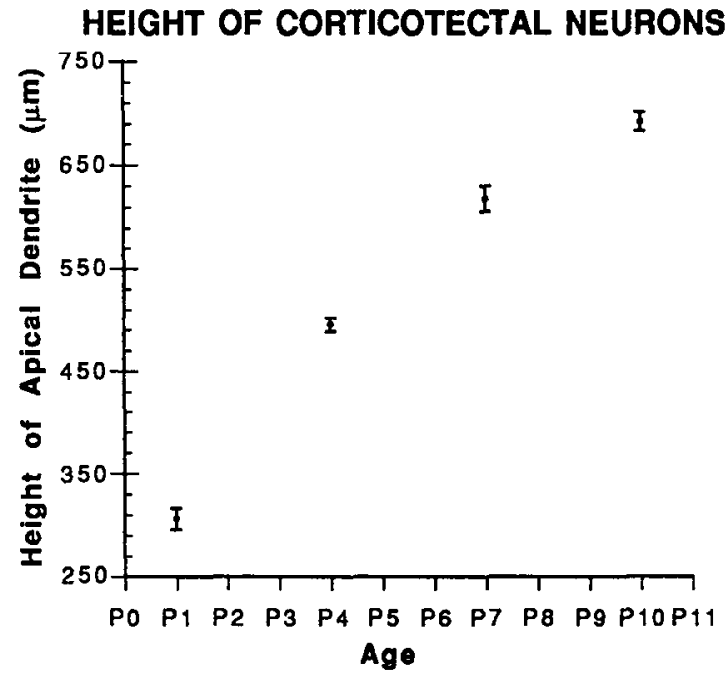

C

CORTICAL THICKNESS

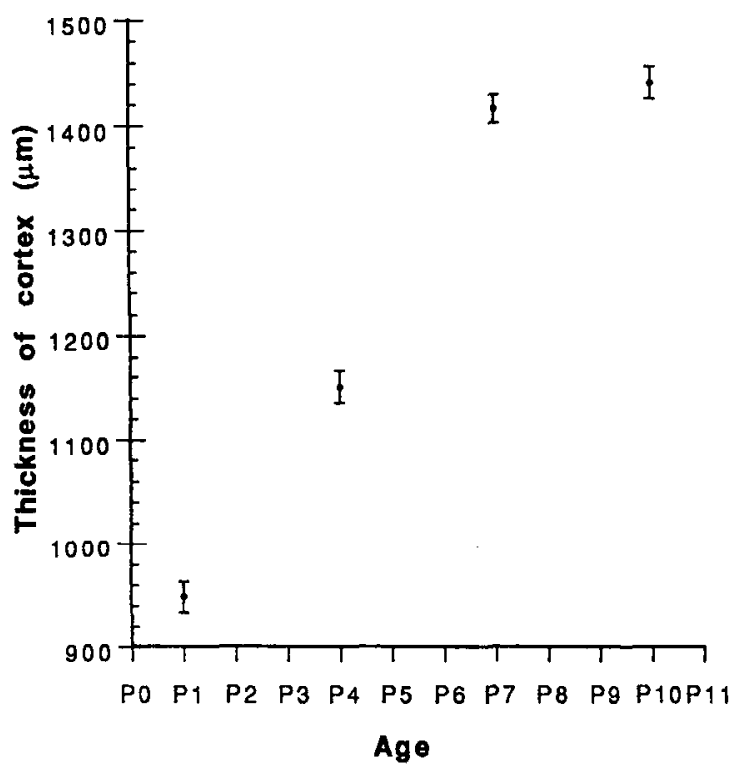

onstrate that the transition of deep callosal neurons from the tall to short pyramidal morphology requires an active elimination of the superficial segments of their apical dendrites.

\section{Discussion}

Wc have studicd in rats the development of the characteristic difference between callosal and corticotectal neurons in the laminar arrangement of their apical dendrites. We show that this distinction does not arise ab initio, but develops through a process of selective dendritic elimination that occurs in a neuronal class-specific as well as a lamina-specific manner. From the earliest ages that we can define callosal and corticotectal neurons, through approximately P5, neurons of each projection class have an apical dendrite in layer 1 , which elaborates a highly branched tuft in layer 1 as the basal dendrites begin to develop. Late in the first postnatal week, dendritic development of the two projection classes diverges dramatically as layer 5 callosal neurons begin to take on their characteristic short pyramidal morphology. Both layer 5 corticotectal neurons and callosal neurons superficial to layer 5 retain an apical dendrite in layer 1 .

\section{Mechanisms that control selective dendritic remodeling}

A priori, two mechanisms could account for the generation of the short pyramidal morphology of layer 5 callosal neurons from their initially tall morphology. An apparent shortening of the apical dendrite could occur as a result of the expansion of the superficial cortical layers without a comparable growth of the dendritic arbor. Alternatively, the apical dendrites of deep callosal neurons could be actively eliminated. Each of these mechanisms plays a key role in the development of axonal projections. For example, in the retinotectal projection of frogs and fishes, terminal arbors of retinal ganglion cell axons initially cover a larger percentage of the surface area of the optic tectum than they will cover at mature stages. This change is not brought about by a decrease in arbor size; rather, arbors increase in absolute size, but over the same period the tectum expands a greater amount, resulting in increased precision in the visuotopic map (Sakaguchi and Murphey, 1985; Stuermer, 1988; Stuermer and Raymond, 1989). In contrast, cortical layer 5 neurons generate their adult patterns of subcortical axonal projections by selectively eliminating collaterals or segments of their primary axons that are functionally inappropriate for the area of cortex in which the neuron is located (Stanfield et al., 1982; Stanfield and O'Leary, 1985; O'Leary and Terashima, 1988; O'Leary et al., 1990).

Our findings demonstrate that the short pyramidal morphology of deep callosal neurons is generated by an active elimi-

Figure 7. Heights of layer 5 callosal and corticotectal neurons, and cortical thickness. Values are presented as means \pm SEM. The numbers of retrogradely labeled callosal (cc) and corticotectal (ct) neurons measured at each age are $\mathrm{P} 1: \mathrm{cc}, 16 ; \mathrm{ct}, 6 ; \mathrm{P} 4: \mathrm{cc}, 16 ; \mathrm{ct}, 63 ; \mathrm{P} 7: \mathrm{cc}, 38$; $\mathrm{ct}$, $47 ; \mathrm{P} 10: \mathrm{cc}, 15 ; \mathrm{ct}, 30$. The height of layer 5 callosal neurons rises until $\mathrm{P} 4$, after which it drops significantly from $\mathrm{P} 4$ to $\mathrm{P} 7$ and from $\mathrm{P} 7$ to $\mathrm{P} 10$ (Student's $t$ test, $p<0.01$ ). Corticotectal cell height and cortical thickness increase over the same time period. The average height of corticotectal neurons is shorter than that of callosal neurons at each age because we selected neurons deep in layer 5 for measurements in callosal cases to avoid including callosal neurons on the border of layers 4 and 5 , some of which retain their layer 1 apical dendrites (see also relative positions compared to $5 / 6$ border in Fig. 6). Measurement criteria are described in Materials and Methods. 
nation of the superficial parts of the apical dendrite. First, layer 4 , the layer in which the apical dendrites of deep callosal neurons usually end in the adult, becomes recognizable by P4 (Wise et al., 1979), an age at which deep callosal neurons still exhibit a tall morphology with their apical dendrite extending into layer 1. Second, the absolute height of the apical dendrite of layer 5 callosal neurons decreases substantially as their short pyramidal morphology emerges. However, since cortical expansion occurs over the same period, we cannot exclude the possibility that passive displacement contributes to the eventual laminar positioning of the apical dendrite. The active elimination of the apical dendrite superficial to layer 4 might occur by either resorption or degeneration, possibilities not distinguished by our labeling method.

Previous reports indicate that in adult rats all deep callosal neurons have a short pyramidal morphology and all corticotectal neurons have a tall pyramidal morphology (Games and Winer, 1988; Hallman et al., 1988; Hübener and Bolz, 1988). At the earliest age that corticotectal neurons can be identified, that is, from the time that their axons first reach the superior colliculus on P1 (DeCarlos and O'Leary, 1992), we have determined that every retrogradely labeled corticotectal neuron extends an apical dendrite into layer 1. Callosal neurons develop in a similar way. On E21, P1, and P4, at least $97 \%$ of the retrogradely labeled deep callosal neurons extend an apical dendrite into layer 1; the small percentage of apical dendrites that do not appear to extend into layer 1 end bluntly, indicating that they have been sectioned. Thus, at perinatal ages essentially all deep layer callosal neurons extend their apical dendrite into layer 1 ; all of them eventually eliminate this dendritic elaboration. All corticotectal neurons, though, retain an apical dendrite to layer 1 . Therefore, the extension of an apical dendrite into layer 1 , and the later decision to eliminate or retain this dendritic scgment are absolute phenomena in that all members of each neuronal population behave in the same way. Thus, the mechanisms responsible for these phenomena not only are highly specific for neuronal class and laminar location within a class, but also are very effective.

Other forms of dendritic remodeling during normal development have been previously reported. These reports usually describe a generalized loss of secondary and tertiary branches and spines as dendritic arbors mature and expand (Weiss and Pysh, 1978; Ramoa et al., 1987, 1988; Dann et al., 1988; Rihn and Claiborne, 1990). A few studies have noted a reduction in the number of primary dendrites (Smith, 1981), a phenomenon that can lead to a bias in the orientation of the dendritic tree (O'Leary and Cowan, 1982; Greenough and Chang, 1988). Further, minor changes in dendrites can occur over time in normal adult animals (Purves et al., 1986).

These previous reports of dendritic remodeling focus on changes that take place within a given neuronal population and are typical of all members of the population. Any mechanism, though, proposed to control the loss of the superficial parts of the apical dendrites of deep callosal neurons must be consistent with the observation that both superficial callosal neurons and corticotectal neurons retain apical dendrites to layer 1 . The distinct behaviors of layer 5 callosal and corticotectal neurons, cells intermingled in the same cortical layer, indicate that they have other underlying differences. At one extreme, the loss of the apical dendrite by deep-layer callosal neurons may be a programmed event that is expressed late in development. Previous observations suggest that the axonal distinctions between these two classes of projection neurons, apparent from the earliest stages of axon outgrowth, are due to inherent differences (Koester and O'Leary, 1989). Other evidence supports the notion that at least basic dendritic form is also intrinsically encoded. For example, dissociated hippocampal or cortical pyramidal neurons will develop appropriate morphologies in culture (Banker and Cowan, 1977, 1979; Kriegstein and Dichter, 1983). Further, patterns of neurites formed in vitro by sister neuroblastoma cells are much more similar to one another than to patterns formed by other cells in the same culture environment (Solomon, 1979). However, the hypothesis that the loss of the apical dendrite by deep callosal neurons is preprogrammed would require that more superficially located callosal neurons lack this program, or that the program limits the mature, although not the developing, height of the apical dendrite of callosal neurons. It might be possible to test this hypothesis by determining the dendritic arrangement of callosal and corticotectal neurons in the mutant reeler mouse, in which cortical layers are inverted due to a defect in the migration of cortical neurons (Caviness, 1976, 1982).

Interactions that occur in the axonal target of a neuron can play a role in determining its dendritic morphology (Jellies et al., 1987; Loer et al., 1987). However, interactions that may occur in the contralateral cortex, the target of callosal axons, probably do not lead to the loss of the apical dendrite of deep callosal neurons. As discussed in the following section, neurons that lose their callosal axon and neurons that retain it both lose their apical dendrite. Furthermore, Weisskopf and Innocenti (1991) have recently reported that lesioning contralateral cortex during development does not affect the dendritic morphology of layer 3 and 4 callosal neurons. A more plausible scenario is that the fate of the apical dendrite may be controlled by extrinsic influences that operate in the cortical environment common to both callosal and corticotectal neurons and that inherent differences between the two projection classes result in their different responses. Such a model would require that, among callosal neurons, those in the deep layers are specifically responsive. One potential extrinsic influence is afferent input. Modifications in afferent input during development lead to an altered dendritic form in many cell types, including spinal motor neurons (Goldstein et al., 1990), Mauthner neurons (Goodman and Model, 1988; but see Kimmel et al., 1990), neurons in brainstem auditory nuclei (Levi-Montalcini, 1949), cerebellar Purkinje cells (Altman and Anderson, 1972; Bradley and Berry, 1976), and nonpyramidal cells in cerebral cortex (Borges and Berry, 1976; Harris and Woolsey, 1981; McMullen et al., 1988).

If afferents control the fate of the apical dendrite of callosal and corticotectal neurons, potential sites of action are most likely layer 1 or layer 4 . One possibility is that the superficial part of the apical dendrite of deep callosal neurons is eliminated due to insufficient afferent input, perhaps because it may be at a competitive disadvantage for layer 1 afferents. The dendrites of a variety of cortical cell types extend into layer 1 , and afferents from numerous sources extrinsic and intrinsic to cortex terminate in layer 1 (Marin-Padilla, 1984). Experimental studies of developing retinal ganglion cells (Linden and Perry, 1982; Perry and Linden, 1982; Perry and Maffei, 1988) and primary motor neurons (Kurz et al., 1989) suggest that competition between dendrites can control the size and geometry of developing dendritic trees. In contrast to a simple competitive model, afferents ending in layer 4 , the layer in which the superficial parts of the apical dendrites of deep callosal neurons end in adults, may promote the removal of more superficial parts of the apical 
dendrite. The thalamocortical projection is the major extrinsic source of cortical afferents and terminates predominantly in layer 4. In rats, a substantial number of thalamic axons invade layer 4 before $\mathrm{P} 2$ and form a dense arborization in it by $\mathrm{P} 4$ (Reinoso and O'Leary, 1990), a day before we see any indication of a regression of apical dendrites. Thalamocortical afferents can influence the orientation of the dendrites of layer 4 stellate neurons (Valverde, 1968; Borges and Berry, 1976; Harris and Woolsey, 1981) and may even promote the removal of an apical dendrite transiently extended by these interneurons (Peinado and Katz, 1990). However, enthusiasm for the role of extrinsic afferents in generating the short pyramidal morphology of deep callosal neurons must be tempered by the observation that unidentified deep layer neurons with short and tall pyramidal morphologies are found in cortical slices taken from neonatal rats and grown in vitro for 2 weeks or more (Bolz et al., 1990). This finding suggests that deep callosal and corticotectal neurons may develop the distinctive laminar arrangements of their apical dendrites in the absence of any afferent inputs that arise from sources outside of the cortcx. Therefore, if afferents do play a role in this process, intracortical afferents, which also terminate densely in layer 4 (Gilbert, 1983; Martin, 1984), are a prime candidate.

\section{Generalizing the initial development of a layer 1 apical dendrite across classes of cortical neurons}

Although we have focused principally on two major classes of cortical projection neurons found in layer 5, callosal and corticotectal, our findings can be extended to other populations of cortical neurons. First, at early stages of cortical development, we could not discriminate between neurons that will form layers 5 and 6 , but since we find that essentially all retrogradely labeled deep callosal neurons have a layer 1 apical dendrite at these stages, we can infer that layer 6 callosal neurons are included in this population. Therefore, layer 6 callosal neurons, which have a short pyramidal morphology in adults (Lorente de Nó, 1949), also develop their form through the selective elimination of an early layer 1 apical dendrite. Second, our results suggest that deep-layer neurons that form ipsilateral intracortical projections, which in adult cat exhibit the short pyramidal morphology (Hübener et al., 1990), also transiently extend an apical dendrite into layer 1 . Callosal neurons are widely distributed over the tangential plane of the developing cortex but become restricted to their limited adult distributions through the selective elimination of callosal axons, leaving large expanses of cortex virtually devoid of callosally projecting neurons (Innocenti, 1981; O'Leary et al., 1981; Ivy and Killackey, 1982; Chalupa and Killackey, 1989); neurons that lose their callosal axon permanently maintain a projection in ipsilateral cortex (Ivy and Killackey, 1982; Chalupa and Killackey, 1989). In rodents, the loss of callosal axons begins during the first postnatal week and is complete by the middle of the third week (Ivy and Killackey, 1979; Olavarria and Van Sluyters, 1985). It follows, then, that a substantial proportion of the transiently "tall" callosal neurons labeled in our study at late fetal and early postnatal ages will lose their callosal axon, as well as their apical dendrite to layer 1, to become the "short" ipsilateral intracortical projection neurons described by Hübener et al. (1990).

Our findings on corticotectal neurons can be generalized to layer 5 neurons that project to other cortical targets in the midbrain, hindbrain, and spinal cord. During development in rodents, layer 5 projections to these subcortical targets are formed exclusively by collaterals that branch from a primary axon that projects to the spinal cord (O'Leary and Terashima, 1988, 1989). For example, the corticotectal projection is a collateral projection of the spinally directed, layer 5 primary axons; many if not all of these primary corticospinal axons form collaterals to multiple subcortical targets (O'Leary and Stanfield, 1985; Bicknese and O'Leary, 1990). Each type of layer 5 subcortical projection neuron classically defined in the adult, for example, corticospinal, corticorubral, corticopontine, and corticobulbar, appears to arise during development from the same population as corticotectal neurons (O'Leary et al., 1990).

The pyramidal morphologies considered in our study predominate in cortical layers $2,3,5$, and 6 . The other major morphological type of cortical neuron is the stellate cell, which populates layer 4 of sensory cortical areas and has a starlike arrangement of dendrites emanating from the soma and mainly confined to the same layer (Peters and Jones, 1984). Peinado and Katz (1990) have presented preliminary evidence suggesting that layer 4 stellate cells initially extend an apical dendrite to layer 1 and only later lose this dendrite and develop their mature stellate morphology. This finding, taken together with the present results, leads to the intriguing possibility that most, if not all, types of cortical neurons initially develop a radial morphology typified by an apical dendrite extending to the pial surface, and that many of the nonpyramidal morphologies characteristic of the adult cortex are the product of later developmental events. An elucidation of the factors that control thesc events is crucial for defining the mechanisms that establish the functional architecture of the adult cortex.

\section{References}

Altman J, Anderson WJ (1972) Experimental reorganization of the cerebellar cortex. I. Morphological effects of elimination of all microneurons with prolonged $\mathrm{x}$-irradiation started at birth. J Comp Neurol 146:355-406.

Banker GA, Cowan WM (1977) Rat hippocampal neurons in dispersed cell culture. Brain Res 126:397-425.

Banker GA, Cowan WM (1979) Further observations on hippocampal neurons in dispersed cell culture. J Comp Neurol 187:469-494.

Bayer SA, Altman J (1991) Neocortical development, p 222. New York: Raven

Bicknese AM, O'Leary DDM (1990) Axon targeting potentials of layer 5 projection neurons across the developing cortex. Soc Neurosci Abstr 16:311.

Bolz J, Novak N, Götz M, Bonhoeffer T (1990) Formation of targetspecific neuronal projections in organotypic slice cultures from rat visual cortex. Nature 346:359-362.

Borges S, Berry M (1976) Preferential orientation of stellate cell dendrites in the visual cortex of the dark-reared rat. Brain Res 112:141147.

Bradley P, Berry M (1976) The effects of reduced climbing and parallel fibre input on Purkinje cell dendritic growth. Brain Res 109:133-151.

Catalano S, Killackey HP (1989) Early ingrowth of individual axons into rat neocortex. Soc Neurosci Abstr 15:874.

Catsmann-Berrevoets CE, Lemon RN, Verburgh CA, Bentivoglio M, Kuypers HGJM (1980) Absence of callosal collaterals derived from rat corticospinal neurons. Exp Brain Res 39:433-440.

Caviness VS Jr (1976) Patterns of cell and fiber distribution in the neocortex of the reeler mutant mouse. J Comp Neurol 170:435-448.

Caviness VS Jr (1982) Neocortical histogenesis in normal and reeler mice: a developmental study based on $\left[{ }^{3} \mathrm{H}\right]$ thymidine autoradiography. Dev Brain Res 4:293-302.

Chalupa LM, Killackey HP (1989) Process elimination underlies ontogenetic change in the distribution of callosal projection neurons in the postcentral gyrus of the fetal rhesus monkey. Proc Natl Acad Sci USA 86: 1076-1079.

Dann JF, Buhl EH, Peichl L (1988) Postnatal dendritic maturation of alpha and beta ganglion cells in cat retina. J Neurosci 8:1485-1499. 
De Carlos JA, O'Leary DDM (1992) Growth and targeting of subplate axons and establishment of major cortical pathways. J Neurosci 12: 1194-1211.

Games KD, Winer JA (1988) Layer V in rat auditory cortex: projections to the inferior colliculus and contralateral cortex. Hearing Res $34: 1-26$.

Gilbert CD (1983) Microcircuitry of the visual cortex. Annu Rev Neurosci 6:217-247.

Godement P, Vanselow J, Thanos S, Bonhoeffer F (1987) A study in developing visual systems with a new method of staining neurones and their processes in fixed tissue. Development 101:697-713.

Goldstein LA, Kurz EM, Sengelaub DR (1990) Androgen regulation of dendritic growth and retraction in the development of a sexually dimorphic spinal nucleus. J Neurosci 10:935-946.

Goodman LA, Model PG (1988) Superinnervation enhances the dendritic branching pattern of the Mauthner cell in the developing axolotl. J Neurosci 8:776-791.

Greenough WT, Chang F-LF (1988) Dendritic pattern formation involves both oriented regression and oriented growth in the barrels of mouse somatosensory cortex. Dev Brain Res 43:148-152.

Hallman LE, Schofield BR, Lin C-S (1988) Dendritic morphology and axon collaterals of corticotectal, corticopontine, and callosal neurons in layer $\mathbf{V}$ of primary visual cortex of the hooded rat. $\mathbf{J}$ Comp Neurol 272:149-160.

Harris RM, Woolsey TA (1981) Dendritic plasticity on mouse barrel cortex following postnatal vibrissa follicle damage. J Comp Neurol 196:357-376.

Hernit CS, Van Sluyters RC, Murphey KM (1990) Visual callosal development in neonatal rats: do migrating or undifferentiated cells have an interhemispheric axon? Soc Neurosci Abstr 16:803.

Honig MG, Hume RI (1989) DiI and DiO: versatile fluorescent dyes for neuronal labelling and pathway tracing. Trends Neurosci 12:333341.

Hübener M, Bolz J (1988) Morphology of identified projection neurons in layer 5 of rat visual cortex. Neurosci Lett 94:76-81.

Hübener M, Schwartz C, Bolz J (1990) Morphological types of projection neurons in layer 5 of cat visual cortex. J Comp Neurol 301: 655-674.

Innocenti GM (1981) Growth and reshaping of axons in the establishment of visual callosal connections. Science 212:824-827.

Ivy GO, Killackey HP (1982) Ontogenetic changes in the projections of neocortical neurons. J Neurosci 2:735-743.

Jellies J, Loer CM, Kristan WB Jr (1987) Morphological changes in leech Retzius neurons after target contact during embryogenesis. J Neurosci 7:2618-2629.

Kimmel CB, Hatta K, Metcalfe WK (1990) Early axonal contacts during development of an identified dendrite in the brain of the zebrafish. Neuron 4:535-545.

Koester SE, O'Leary DDM (1989) Selective axon growth not axon loss produces connectional distinctions between callosal and subcortically projecting layer 5 cortical neurons. Soc Neurosci Abstr 15:960.

Koester SE, O'Leary DDM (1990) Dendritic distinctions between callosal and subcortically projecting pyramidal neurons develop from an initial common morphology by elimination of exuberant apical dendrites. Soc Neurosci Abstr 16:1126.

Kriegstein AR, Dichter MA (1983) Morphological classification of rat cortical neurons in cell culture. J Neurosci 3:1634-1647.

Kurz EM, Goldstein LA, Sengelaub DR (1989) Evidence for dendritic competition in the development of motoneuron morphology in rat spinal cord. Soc Neurosci Abstr 15:67.

Larkman A, Mason A (1990) Correlations between morphology and electrophysiology of pyramidal neurons in slices of rat visual cortex. I. Establishment of cell classes. J Neurosci 10:1407-1414.

Levi-Montalcini R (1949) The development of the acoustico-vestibular centers in the chick embryo in the absence of the afferent root fibers and of descending fiber tracts. J Comp Neurol 91:209-242.

Linden R, Perry VH (1982) Ganglion cell death within the developing retina: a regulatory role for retinal dendrites? Neuroscience 7:28132827.

Loer CM, Jellies J, Kristan WB Jr (1987) Segment-specific morphogenesis of leech Retzius neurons requires particular peripheral targets. J Neurosci 7:2630-2638

Lorente de Nó R (1949) Cerebral cortex: architecture, intracortical connections, motor projections. In: Physiology of the nervous system, 3d ed (Fulton JF, ed), pp 274-301. New York: Oxford UP.
Lund RD, Mustari MJ (1977) Development of the geniculocortical pathway in rats. J Comp Neurol 173:284-306.

Marin-Padilla M (1984) Neurons of layer 1: a developmental analysis. In: Cerebral cortex, Vol 1 (Peters A, Jones EG, eds), pp 447-478. New York: Plenum.

Martin KAC (1984) Neuronal circuits in cat striate cortex. In: Cerebral cortex, Vol 2 (Jones EG, Peters A, eds), pp 241-284. New York: Plenum.

Mason A, Larkman A (1990) Correlations between morphology and clectrophysiology of pyramidal neurons in slices of rat visual cortex. II. Electrophysiology. J Neurosci 10:1415-1428.

McMullen NT, Goldberger B, Suter CM, Glaser EM (1988) Neonatal deafening alters nonpyramidal dendrite orientation in auditory cortex: a computer microscope study in the rabbit. J Comp Neurol 267:92106.

Miller R (1975) Distribution and properties of commissural and other neurons in cat sensorimotor cortex. J Comp Neurol 164:361-374.

Olavarria J, Van Sluyters RC (1985) Organization and postnatal development of callosal connections in the visual cortex of the rat. $\mathrm{J}$ Comp Neurol 239:1-26.

O'Leary DDM, Cowan WM (1982) Further studies on the development of the isthmo-optic nucleus with special reference to the occurrence and fate of ectopic and ipsilaterally projecting neurons. $J$ Comp Ncurol 212:399-416.

O'Leary DDM, Stanfield BB (1985) Occipital cortical neurons with transient pyramidal tract axons extend and maintain collaterals to subcortical but not intracortical targets. Brain Res 336:326-333.

O'Leary DDM, Terashima T (1988) Cortical axons branch to multiple subcortical targets by interstitial axon budding: implications for target recognition and "waiting periods." Neuron 1:901-910.

O'Leary DDM, Terashima T (1989) Growth and branching of cortical axons: implications for target selection by developing axons. Soc Neurosci Abstr 15:875.

O'Leary DDM, Stanfield BB, Cowan WM (1981) Evidence that the early postnatal restriction of the cells of origin of the callosal projection is due to the elimination of axonal collaterals rather than to the death of neurons. Dev Brain Res 1:607-617.

O'Leary DDM, Bickncsc AR, DcCarlos JA, Heffner CD, Kocster SE, Kutka LJ, Terashima T (1990) Target selection by cortical axons: alternative mechanisms to establish axonal connections in the developing brain. Cold Spring Harbor Symp Quant Biol 55:453-468.

Parnavelas JG (1984) Physiological properties of identified neurons. In: Cerebral cortex, Vol 2 (Jones EG, Peters A, eds), pp 205-240. New York: Plenum.

Peinado A, Katz LC (1990) Development of cortical spiny stellate cells: retraction of a transient apical dendrite. Soc Neurosci Abstr 16: 1127.

Perry VH, Linden R (1982) Evidence for dendritic competition in the developing retina. Nature 297:683-685.

Perry VH, Maffei L (1988) Dendritic competition: competition for what? Dev Brain Res 41:195-208.

Peters A, Jones EG (1984) Classification of cortical neurons. In: Cerebral cortex, Vol 1 (Jones EG, Peters A, eds), pp 107-122. New York: Plenum.

Purves D, Hadley RD, Voyvodic JT (1986) Dynamic changes in dendritic geometry of individual neurons visualized over periods of up to three months in the superior cervical ganglion of living mice. J Neurosci 6:1051-1060.

Rall W (1964) Theoretical significance of dendritic trees for neuronal input-output relations. In: Neuronal theory and modelling (RF Reiss, ed), pp 73-79. Stanford: Stanford UP.

Ramoa AS, Campbell G, Shatz CJ (1987) Transient morphological features of identified ganglion cells in living fetal and neonatal retina. Science 237:522-525.

Ramoa AS, Campbell G, Shatz CJ (1988) Dendritic growth and remodeling of cat retinal ganglion cells during fetal and postnatal development. J Neurosci 8:4239-4261.

Reinoso BS, O'Leary DDM (1990) Correlation of geniculocortical growth into the cortical plate with the migration of their layer 4 and layer 6 target cells. Soc Neurosci Abstr 16:493.

Rihn LL, Claiborne BJ (1990) Dendritic growth and regression in rat dentate granule cells during late postnatal development. Dev Brain Res 54:115-124.

Sakaguchi DS, Murphey RK (1985) Map formation in the developing 
Xenopus retinotectal system: an examination of ganglion cell terminal arborizations. J Neurosci 5:3228-3245.

Sandell JH, Masland RH (1988) Photoconversion of some fluorescent markers to a diaminobenzidine reaction product. J Histochem Cytochem 36:555-559.

Silva LR, Amitai Y, Connors BW (1991) Intrinsic oscillations of neocortex generated by layer 5 pyramidal neurons. Science 251:432-435.

Smith ZDJ (1981) Organization and development of brain stem auditory nuclei of the chicken: dendritic development in $\mathrm{n}$. laminaris. J Comp Neurol 203:309-333.

Solomon F (1979) Detailed neurite morphologies of sister neuroblastoma cells are related. Cell 16:165-169.

Stanfield BB, O'Leary DDM (1985) The transient corticospinal projection from the occipital cortex during the postnatal development of the rat. J Comp Neurol 238:236-248.

Stanfield BB, O'Leary DUM, Fricks C (1982) Selective elimination in early postnatal development restricts cortical distribution of rat pyramidal tract neurones. Nature 298:371-373.

Stuermer CAO (1988) Retinotopic organization of the developing retinotectal projection in the zebrafish embryo. J Neurosci 8:4513-4530.

Stuermer CAO, Raymond PA (1989) Developing retinotectal projection in larval goldfish. J Comp Neurol 281:630-640.

Swadlow HA, Weyand TG (1981) Efferent systems of the rabbit visual cortex: laminar distribution of the cells of origin, axonal conduction velocities, and identification of axonal branches. J Comp Neurol 203: 799-822.
Valentino KL, Jones EG (1982) The early formation of the corpus callosum: a light and electron microscopic study in foetal and neonatal rats. J Neurocytol 11:583-609.

Valverde F (1968) Structural changes in the area striata of the mouse after enucleation. Exp Brain Res 5:274-292.

Weiss GM, Pysh JJ (1978) Evidence for loss of Purkinje cell dendrites during late development: a morphometric Golgi analysis in the mouse. Brain Res 154:219-230.

Weisskopf M, Innocenti GM (1991) Neurons with callosal projections in visual areas of newborn kittens: an analysis of their dendritic phenotype with respect to the fate of the callosal axon and its target. Exp Brain Res 86:151-158.

Wise SP, Jones EG (1976) The organization and postnatal development of the commissural projection of the rat somatic sensory cortex. J Comp Neurol 168:313-344.

Wise SP, Jones EG (1977) Cells of origin and terminal distribution of descending projections of the rat somatic sensory cortex. J Comp Neurol 175:129-158.

Wise SP, Fleshman JW, Jones EG (1979) Maturation of pyramidal cell form in relation to developing afferent and efferent connections of rat somatic sensory cortex. Neuroscience 4:1275-1297.

Wong D, Kelly JP (1981) Differentially projecting cells in individual layers of the auditory cortex: a double-labeling study. Brain Res 230: 362-366. 